\title{
Thermal Simulation of the Continuous Pulse Discharge for Electro-spark Deposition Diamond Wire Saw
}

Chengyun Li

Shandong University

Peiqi Ge ( $\square$ pqge@sdu.edu.cn )

Shandong University

Wenbo Bi

Shandong University

\section{Research Article}

Keywords: Diamond wire saw, ESD, Continuous pulse discharge, Thermal analysis

Posted Date: June 9th, 2021

DOI: https://doi.org/10.21203/rs.3.rs-585874/v1

License: (1) This work is licensed under a Creative Commons Attribution 4.0 International License. Read Full License

Version of Record: A version of this preprint was published at The International Journal of Advanced Manufacturing Technology on January 4th, 2022. See the published version at https://doi.org/10.1007/s00170-021-08444-x. 
3 Chengyun $\mathrm{Li}^{1}$, Peiqi $\mathrm{Ge}^{1,2 *}$, Wenbo $\mathrm{Bi}^{1}$

4 1. School of Mechanical Engineering, Shandong University, Jinan 250061, China

5 2. Key Laboratory of High-Efficiency and Clean Mechanical Manufacture at Shandong University, Ministry of Education, Jinan 250061, China

*Corresponding author. Tel. /Fax.: +86 531 88399277. Email: pqge@ sdu.edu.cn

8 Email address: cyli@mail.sdu.edu.cn (Chengyun Li), pqge@sdu.edu.cn (Peiqi Ge),

9 biwenbo@sdu.edu.cn (Wenbo Bi).

\section{Abstract}

Due to their excellent physical and mechanical properties, third-generation super-hard semiconductor materials (such as $\mathrm{SiC}, \mathrm{GaN}$ ) are widely used in the field of microelectronics. However, due to its ultra-high hardness, the machining is very difficult, which has become the bottleneck of its development. The electro-spark deposition (ESD) process can deposit electrode materials on the substrate under the condition of low heat input to achieve metallurgical bonding between metal materials. And it can improve the wear resistance, corrosion resistance, and repair the size of the workpiece. It has been widely used in the field of surface modification engineering. It can effectively improve the bonding strength of the abrasive grains, and the sawing ability of the wire saw to make the consolidated diamond wire saw by the ESD process. Due to its thin matrix and poor thermal properties, the saw wire is easy to burning or even breaking in the manufacturing process. At present, the selection of pulse interval time in the ESD process is generally determined by the duty factor. However, the pulse interval time selected according to duty factor is difficult to meet the heat dissipation requirements of electro-spark deposition diamond wire saw (ESDDWS). In this paper, two kinds of motion modes of ESDDWS manufacturing are put forward, according to the manufacturing characteristics of ESDDWS. The boundary conditions of the continuous pulse discharge of ESDDWS are established. The thermal simulations of continuous pulse discharge of ESDDWS under two

31 motion modes are analyzed. According to the simulation results, the basis of the value 32 of pulse interval in the ESDDWS process is put forward. The effect of pulse interval time on the mechanical performance of the wire saw is analyzed experimentally. The 
can ensure the continuous production of the ESDDWS.

36 Keywords: Diamond wire saw, ESD, Continuous pulse discharge, Thermal analysis

37 Nomenclature

$\begin{array}{ll}c & \text { Specific heat capacity } \\ h & \text { Convection heat coefficient } \\ k & \text { Discharge current } \\ m & \text { Thermal conductivity } \\ q_{0} & \text { Number of discharge } \\ R & \text { Maximum heat flux } \\ R_{j} & \text { The radius of the plasma channel } \\ r & \text { The radius of the saw wire } \\ T & \text { Coordinates of cylindrical work domain } \\ T_{0} & \text { Temperature } \\ t & \text { Environment temperature } \\ t_{\text {on }} & \text { Time } \\ t_{o f f} & \text { Pulse duration time } \\ z & \text { Pulse interval time } \\ \beta & \text { Coordinates of cylindrical work domain } \\ \theta & \text { The angle between the incident direction of the heat flow and the } \\ \rho & \text { normal direction at a point on the core wire surface } \\ & \text { Coordinates of cylindrical work domain }\end{array}$

\section{Introduction}

39 The third-generation semiconductor materials (such as $\mathrm{SiC}$ and $\mathrm{GaN}$ ) have the

40 characteristics of a high breakdown field, great charge carrier saturation, and elevated

41 dissociation temperatures. It can meet the new requirements of modern electronic

42 technology for high temperature, high voltage, high frequency, high power, and

43 radiation resistance $[1,2]$. Therefore they have a broad application prospect in the

44 field of microelectronics [3, 4]. From the crystal bar to wafers, crystal machining

45 mainly includes slicing, grinding, and polishing. Slicing is the first machining

46 procedure that directly affects the subsequent processes $[5,6]$. However, due to its

47 ultra-high hardness, the machining is very difficult, which has become the bottleneck

48 of its development [7].

49 Fixed diamond wire saw has become the main tool for slicing hard and brittle

50 materials $[8,9]$. At present, fixed diamond wire saw mainly includes resin diamond 
wire saw and electroplated diamond wire saw. The diamonds are attached to a core wire by resin or electroplated [10]. Diamonds are less strongly bonded and have shorter service life due to easy drop-off and wear of the abrasive layer [11]. Slicing the super hard crystal is very difficult and inefficient [12]. In order to improve the slicing efficiency, it is necessary to improve the holding strength and wear resistance of the DWS.

ESD is a deposition process in which the electrode material is deposited on the metal substrate by applying a short duration and high current pulse between cathode and anode $[13,14]$. It has become the new surface treatment technology that improves the wear resistance and corrosion resistance of workpieces. Many research results show that the substrate can be kept close to room temperature with less heat input, and the mechanical properties of the substrate can be maintained [15]. Obviously, this is only for large-size workpieces. Adam et al. [16] found that the range of the heat-affected zone was 10 to $20 \mu \mathrm{m}$. At present, the diameter of the DWS matrix is 50 to $450 \mu \mathrm{m}$, and there is a decreasing trend. Therefore, the thermal effect on the saw wire can not be ignored during the ESDDWS process. It is necessary to research the temperature field in the continuous pulse discharge of the ESDDWS process. The discharge interval is an important factor in the ESD process. It influences the discharge state and heat diffusion [17]. However, there are little researches on the selection of pulse interval time in the ESD process. And it is determined mainly by the duty factor. Jain et al. [18] considered that the duty factor of ESD could be between $40 \%$ and $86 \%$. He has studied the influence of the duty factor on the height and width of the deposition layer through experiments. The results show that the height and width of the deposition layer increase with the increase of the duty factor. Mohri et al. [19] considered that the duty factor of the ESD should be less than 6\%. Furutani et al. [20-22] fabricated wire saw in kerosene medium by ESD, and the duty factor was $3 \%$. However, it was found that the wire is broken frequently when the current exceeds a certain range during the fabrication process. Obviously, the ESDDWS process is different from the surface treatment for the large-size workpiece. Because the size of the workpiece is hundreds or even thousands of times larger than the size

81 of the discharge channel, the local temperature of deposition point has little effect on 82 the overall temperature of the substrate, which can make the workpiece almost keep at room temperature. Due to its thin diameter and poor heat dissipation performance, the saw wire is sensitive to the temperature increasing during the ESDDWS process. 
forward, according to the manufacturing characteristics of ESDDWS. The boundary conditions of continuous pulse discharge of ESDDWS were established. The thermal simulations of continuous pulse discharge of ESDDWS under two motion modes were analyzed. According to the simulation results, the basis of determining the pulse interval time in the ESDDWS process was put forward. The effect of pulse interval time on the mechanical performance of the wire saw is analyzed experimentally. The results show that selected the discharge interval time base on the simulation results can ensure the continuous production of ESDDWS.

\section{The principle of fabrication of ESDDWS}

The principle of fabrication of ESDDWS has been studied [23]. It is not difficult to find the particularities of the ESDDWS process. Generally, the surface modification technology requires a certain thickness of the deposited layer to meet the specific performance requirements, so it needs to be repeated deposition in a certain area. However, the DWS only needs one abrasive layer. Under proper parameters, the requirement of consolidated diamond grains can be satisfied after several pulses or even one pulse of deposition in the ESDDWS process.

(a)

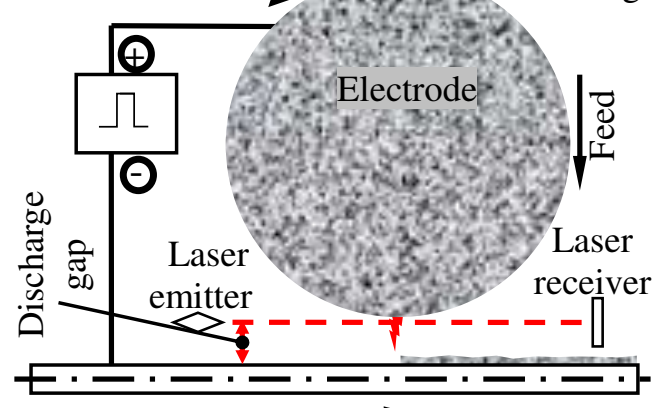

Wire feed

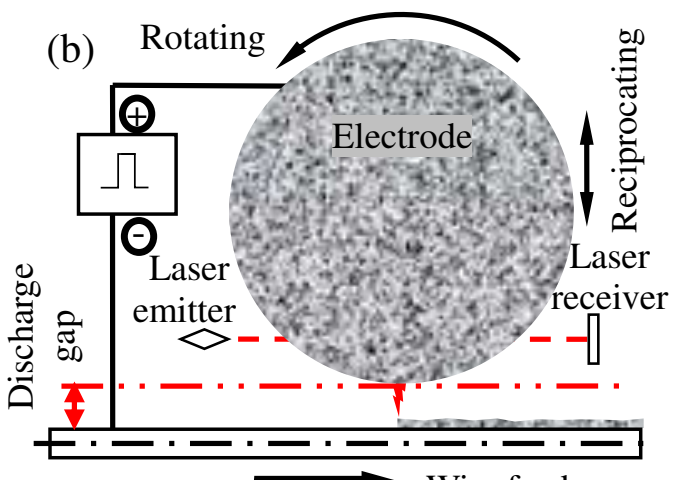

Wire feed

Fig.1 Move model of electrode and wire

According to the characteristics of the ESDDWS process, the movement modes of electrode and wire can be divided into two styles (as shown in Fig.1). (1) During the manufacturing process, the electrode and matrix maintain a fixed gap. The electrodes rotate uniformly and the matrix feeds uniformly. Meanwhile, the circumferential velocity of the electrode is equal to the velocity of the core wire. The feed of the electrode is controlled by a laser limiter. (2) In the manufacturing process, the wire remains stationary during the reciprocating movement of the electrode. When the electrode returns to its original position, the wire moves forward for a distance and the electrodes rotate for an angle. The feed of the electrode is automatically adjusted by reciprocating motion. 
114 In order to simplify the calculation, there are some assumptions made as follows.

115 (1) In the manufacturing process, the arrangement of the core wire and electrodes

116 makes the electrode column face to the surface of the matrix;

117 (2) In the process of manufacturing, the discharge is single-channel discharge and 118 normal spark discharge;

119 (3) The discharge points are at the minimum gap between the core wire and the 120 electrode;

121 (4) The shape of both electrode and core wire is ideal. It is ignoring the change of 122 electrode material consumption and wire surface material accumulation.

\section{$123 \quad 3$ Thermal simulation of ESDDWS}

1243.1 Governing equations of heat conduction

125 For the transient, non-linear thermal analysis of the ESD process, the governing 126 Fourier heat conduction equation [24, 25] is given by Eq. (1):

$$
c \rho \frac{\partial T}{\partial t}=k\left(\frac{\partial^{2} T}{\partial r^{2}}+\frac{1}{r} \frac{\partial T}{\partial r}+\frac{\partial^{2} T}{\partial z^{2}}\right)
$$

127 Where $r$ and $z$ are the coordinates of the cylindrical work domain; $T$ is temperature; $\rho$,

$128 c, k$, and $t$ are mass density, specific heat capacity, thermal conductivity, and time, 129 respectively.

1303.2 Boundary conditions

131 The single discharge surface heat source of the core wire [23] can be given as Eq. 132 (2):

$$
q(\theta, r)=q_{0} \exp \left(-4.5 \frac{r^{2}}{\left(a^{2} \cos ^{2} \theta+b^{2} \sin ^{2} \theta\right)}\right) \cos \beta ;\left\{\begin{array}{l}
R(t)<R_{j}, a=b=R(t) \\
R(t)>R_{j}, a=R(t), b=R_{j}
\end{array}\right.
$$

133 Where $\theta$ is the coordinates of the cylindrical work domain; $\beta$ is the angle between the 134 incident direction of the heat flow and the normal direction at a point on the core wire surface, $\beta=\arcsin \frac{r \cos \theta}{R_{j}}$.

136 Eq. (2) only consider the heat flux on pulse duration time. The continuous pulse 137 discharge boundary conditions of the core wire can be given as Eq. (3)

$$
k \frac{\partial T}{\partial \mathrm{n}}= \begin{cases}q(\varphi, r) ; & m\left(T_{o n}+T_{o f f}\right)<t \leq m\left(T_{o n}+T_{\text {off }}\right)+T_{o n}, 0<r \leq R \\ h\left(T-T_{0}\right) ; & m\left(T_{o n}+T_{o f f}\right)<t \leq m\left(T_{o n}+T_{o f f}\right)+T_{o n}, r>R \\ h\left(T-T_{0}\right) ; & T_{o n}+m\left(T_{o n}+T_{o f f}\right)<t \leq(m+1)\left(T_{o n}+T_{o f f}\right)\end{cases}
$$

138 Where $h$ is the convection heat transfer coefficient; $k$ is the thermal conductivity; $R$ is 139 the radius of the plasma channel; $m$ is the number of discharges. Initial temperatures 
140 of the core wire are assumed to be uniform at environment temperature, $T_{0}=25^{\circ} \mathrm{C}$.

$141 \quad 3.3$ Meshing

142 Generally, the thermal analysis model of ANSYS is a closed model. In single pulse 143 analysis, the heat-affected zone of discharge point is smaller because of the short 144 action time and less heat input. Limited models can already meet the requirements of 145 simulation(shown in Fig.2(a)). However, Due to the long action time and the high 146 total heat input, the limited model can not meet the requirements in the continuous 147 pulse discharge deposition process, which increases the saw wire temperature (shown 148 in Fig.2(b)). Based on the element independence analysis (shown in Fig.3), the 149 element size is determined to be $3 \times 2 \times 2 \mu \mathrm{m}$. Although, increasing the number of 150 elements can alleviate the problem of temperature accumulate without changing the 151 element size. However, increasing the number of elements will result in the 152 calculation time substantial increase.

153 Based on the physical model of the ESDDWS, we can see that the saw wire is slender, 154 and the heat can be transferred infinitely in the axial direction of the core wire during 155 the deposition process. That is, the boundary of the wire saw on the axis is open. In 156 ANSYS software, the far-field element can solve the problem, which is the infinite 157 boundary of heat transfer. For 3D transient thermal simulation, the infin111 unit 158 should be selected. It should be noted that the far-field elements have only one layer 159 and require an infinite boundary load on the outside. According to the symmetry of 160 the saw wire, the meshing model of continuous pulse discharge thermal simulations of 161 ESDDWS is shown in Fig.4.

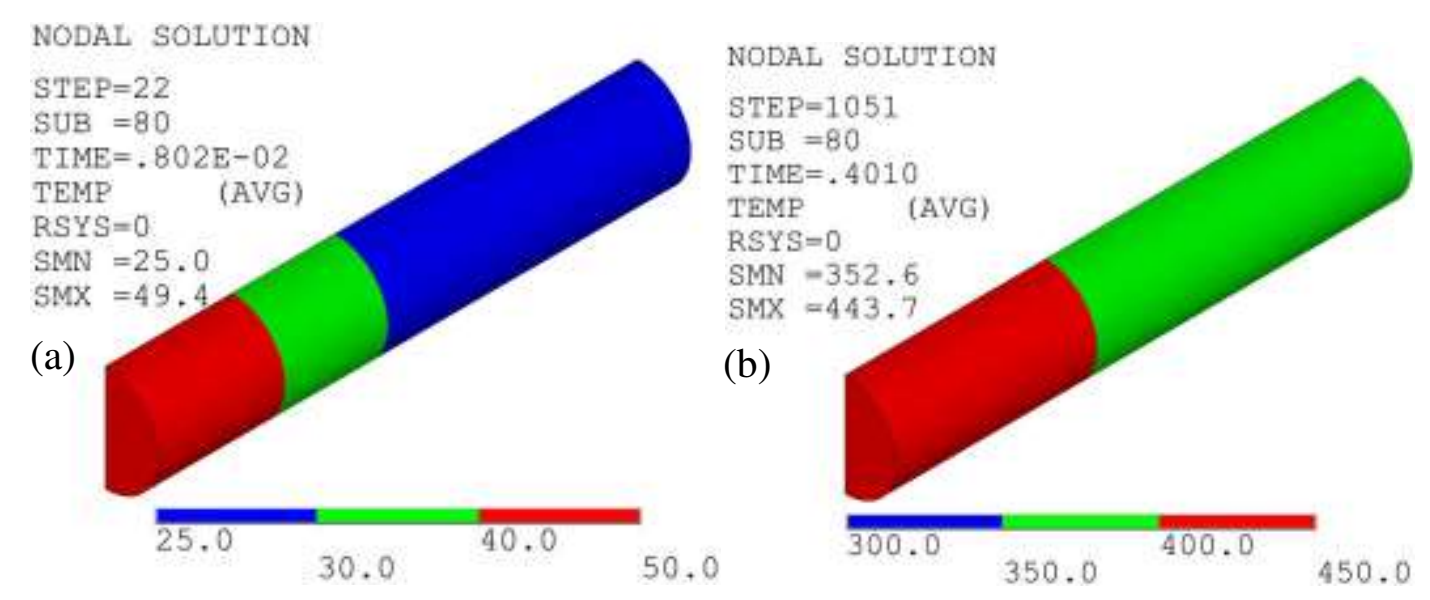
Fig.2 Temperature field of ESDDWS: (a) Single period temperature field; (b) 
(a)

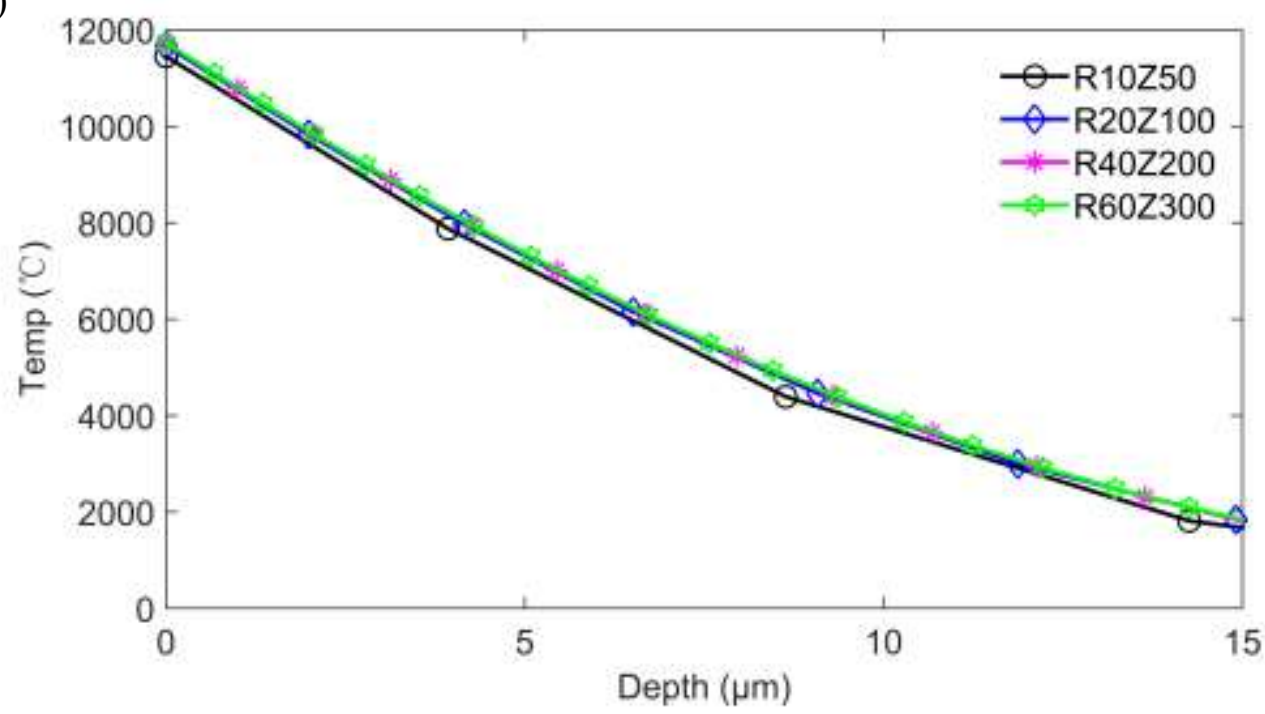

(b)

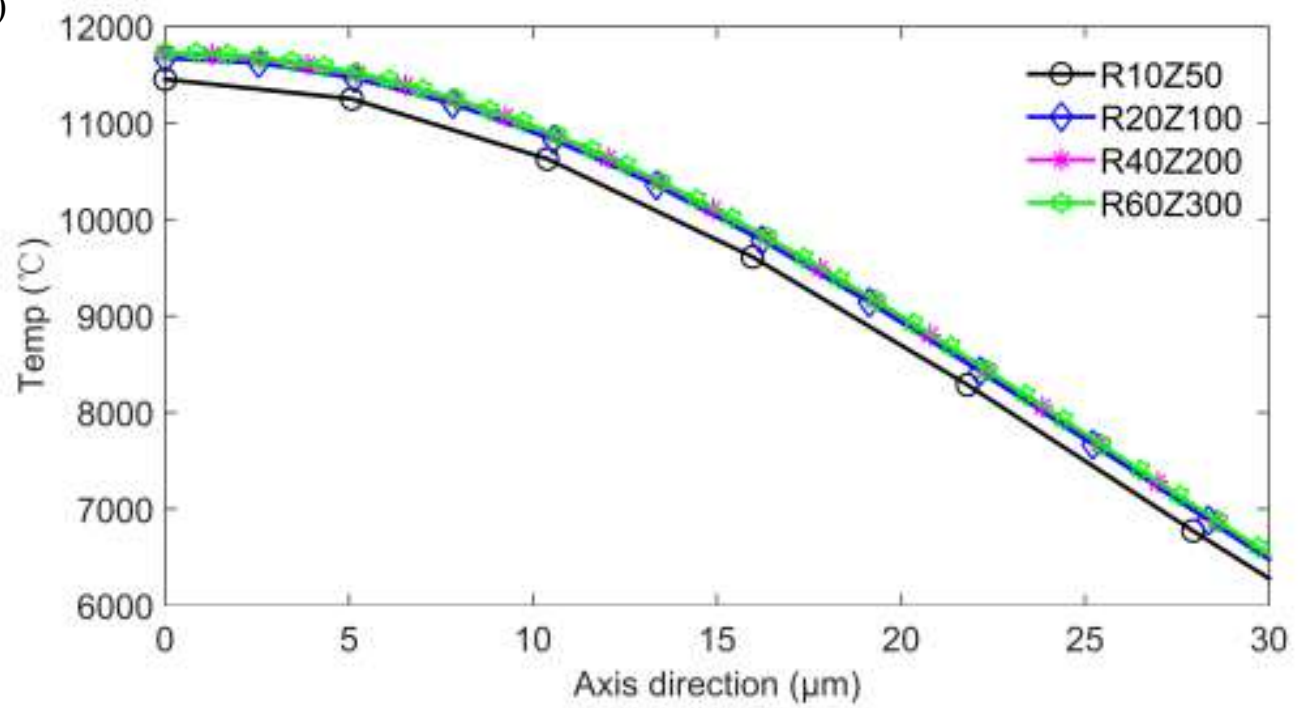

166

167 Fig.3 The element independence analysis: (a) depth direction; (b) axis direction

168

169

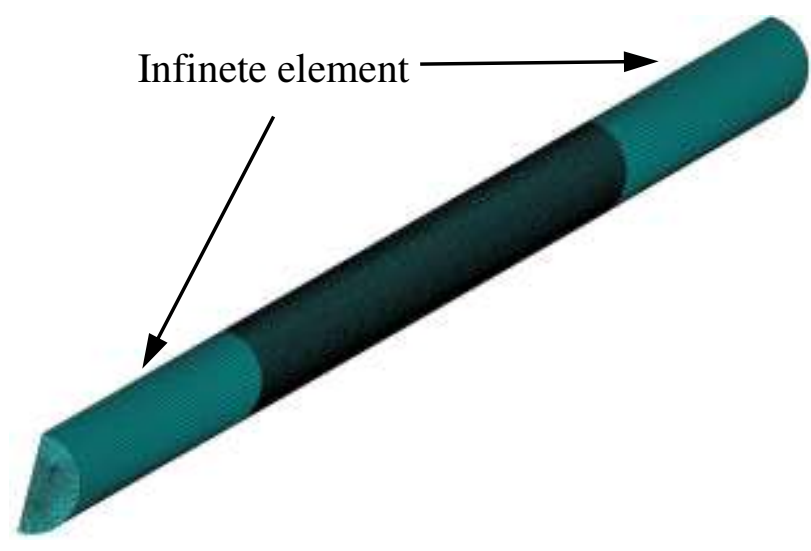

Fig.4 Meshing model of saw wire 


\section{Simulation results and discussion}

171 In this work, the diamond abrasive used W40 Ti coated diamond. The selection of

172 discharge parameters based on the condition, the melting volume of electrode material

173 is the volume of diamond girt's 5, 10, and 15 times. According to the prediction range

174 of the process parameters [23], the discharge parameters determined as follows. The

175 current is $19 \mathrm{~A}$, and the pulse duration time is $12 \mu \mathrm{s}, 20 \mu \mathrm{s}$, and $30 \mu \mathrm{s}$. The thermal

176 simulations of continuous pulse discharge of ESDDWS under two motion modes are

177 analyzed. Under motion mode 1 , when the current is $19 \mathrm{~A}$, the pulse width is $20 \mu \mathrm{s}$, the

178 pulse interval is $600 \mu \mathrm{s}$, and the moving speed is one discharge channel diameter per

179 period. The temperature field of continuous pulse discharge deposition is shown in

180 Fig.5(a). Under motion mode 2, when the current is 19A, the pulse width is $20 \mu \mathrm{s}$, and

181 the pulse interval time is $8 \mathrm{~ms}$. The temperature field of continuous pulse discharge

182 deposition is shown in Fig.5(b).

NODAL SOLUTION

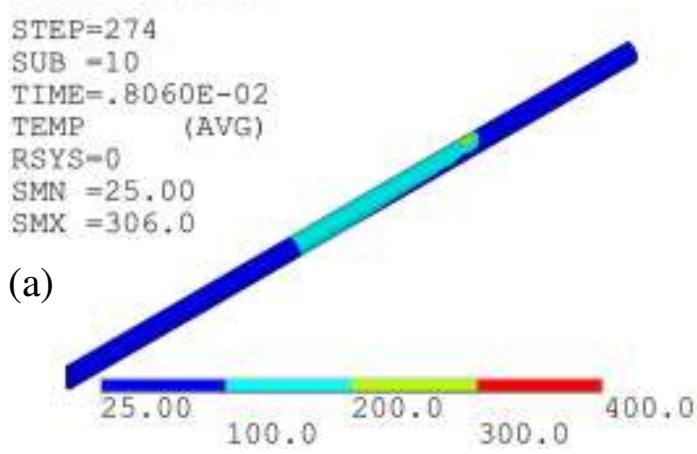

NODAL SOLUTION

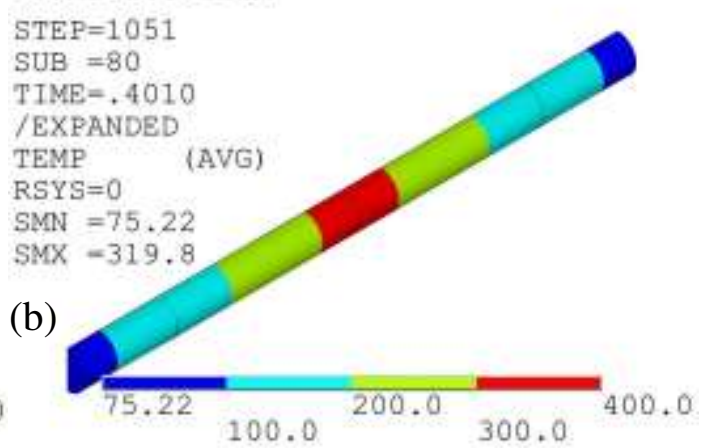

TIME $=.4010$

/EXPANDED

TEMP (AVG)

SMX -319.8

b)

184

Fig.5 Temperature field of continuous pulse discharge deposition: (a) move motion 1; 185

(b) move motion 2

(a)

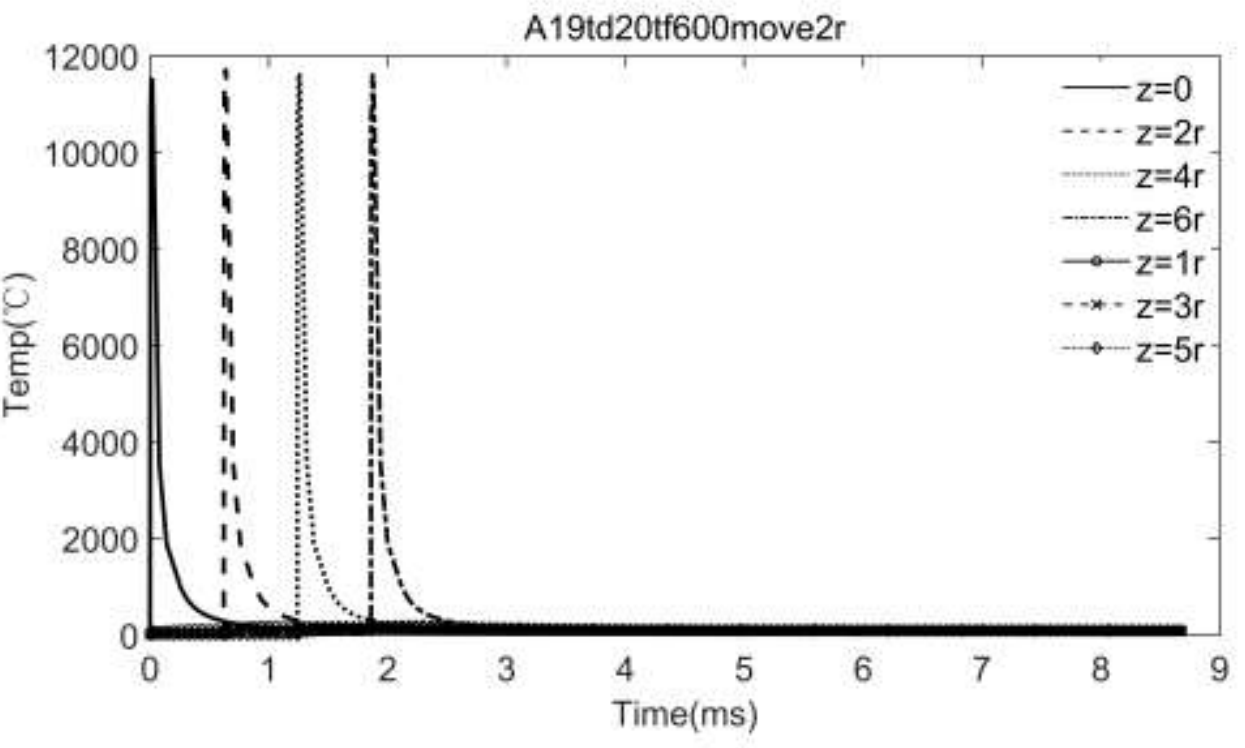


(b)

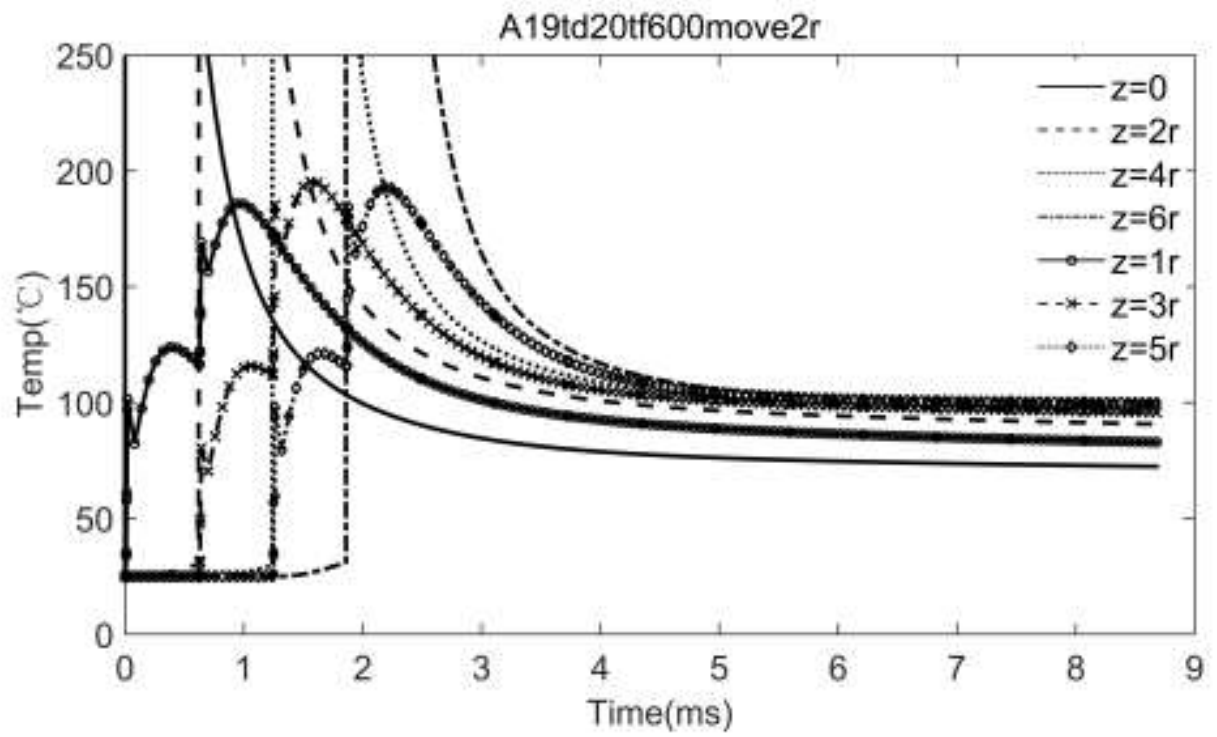

187

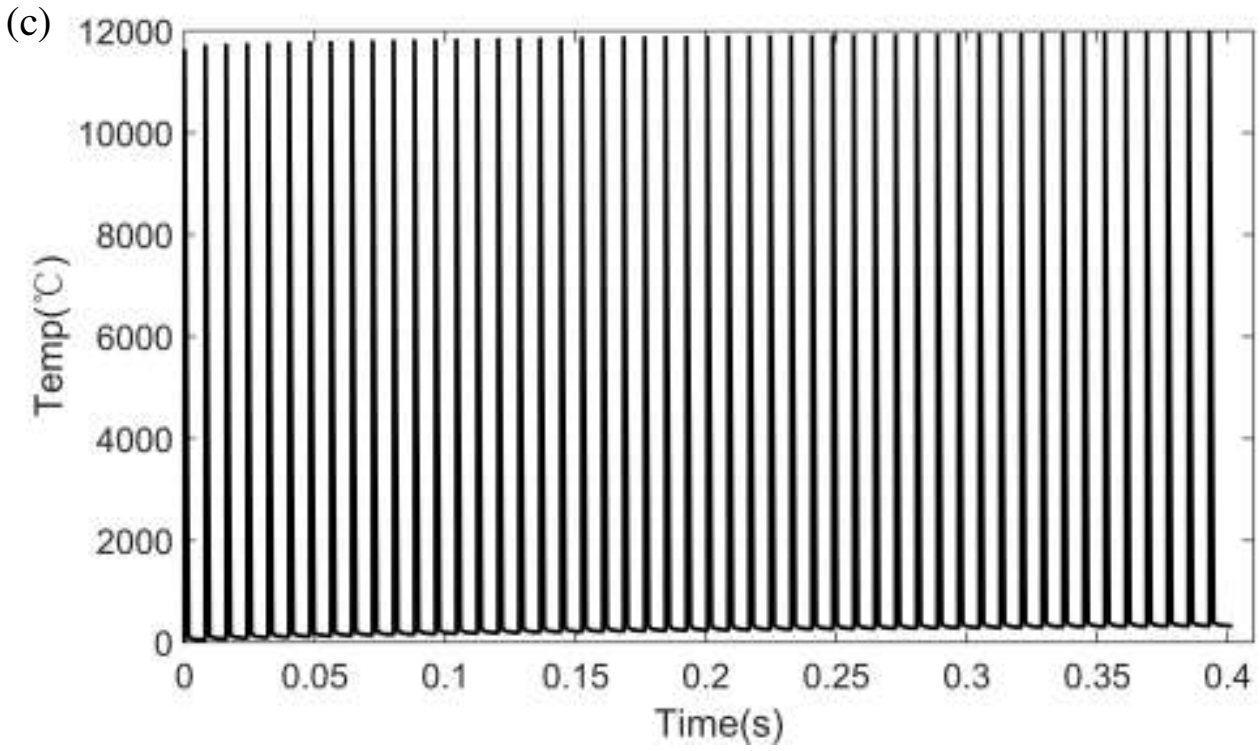

188

(d)

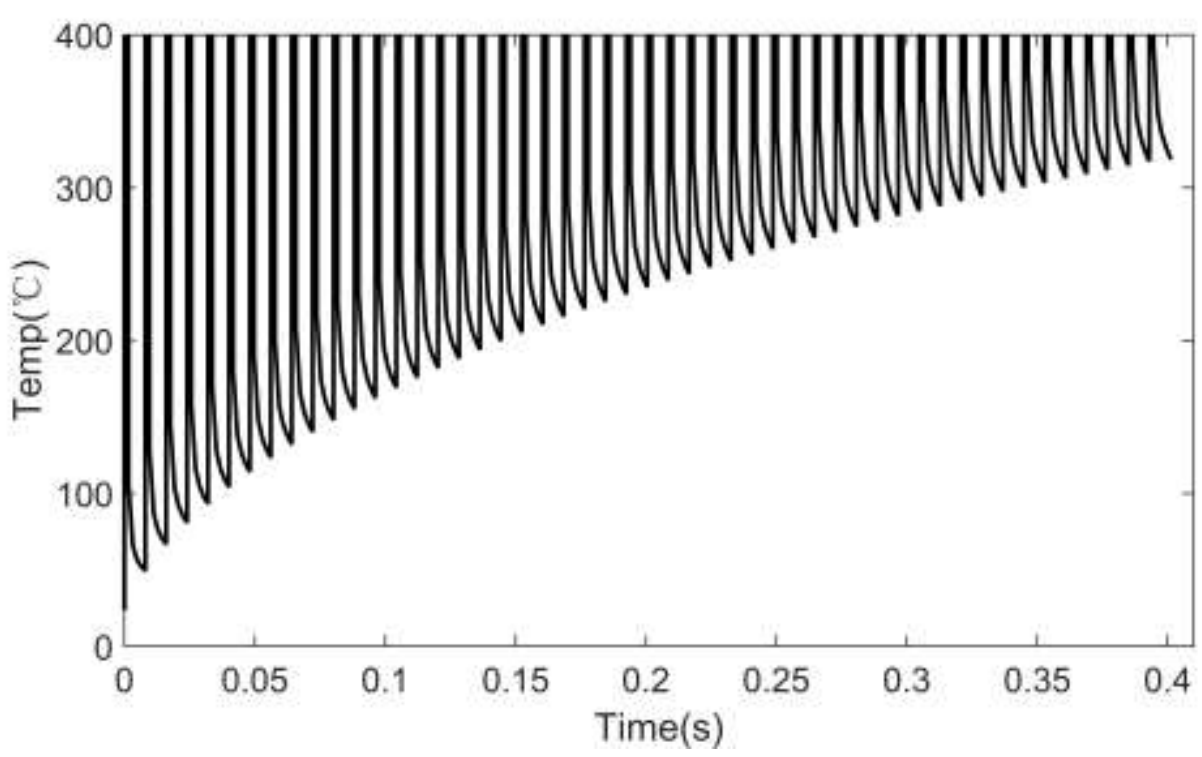


193 From Fig.6(a) and (c), it can be seen that during a discharge period, whatever mode 1

194 or 2, the core wire's temperature rises rapidly, and then decreases rapidly. At the heating stages, the heating rate can reach $6 \times 10^{9} \mathrm{C} / \mathrm{s}$. After discharging, the cooling process can be divided into two stages. At the high-temperature stages, the temperature of the core wire decreases rapidly, and the cooling rate is similar to the heating rate. At the low-temperature stages, the cooling rate decreases gradually. By comparing the temperature curves, it can be seen that there is a big difference between motion modes 1 and 2 . In motion mode 1 , there is no mutation in the temperature-time curves of adjacent discharge centers such as $\mathrm{z}=0, \mathrm{z}=2 \mathrm{r}, \mathrm{z}=4 \mathrm{r}$, and $\mathrm{z}=6 \mathrm{r}$. It indicates that the temperature of the next discharge center is not affected by the previous discharge. There are two abrupt mutations in the temperature curve of the edge point of the discharge channel in a period. And there are four mutations in total such as $\mathrm{z}=\mathrm{r}, \mathrm{z}=3 \mathrm{r}$, and $\mathrm{z}=5 \mathrm{r}$. The first mutation is caused by the heat source and then decreases with the end of discharge. The second mutation is due to the diffusion of a

207 large amount of heat from the discharge center. It indicates that the adjacent 208 discharges have an impact on the edge point of the discharge channel. The effect of 209 temperature superposition can be ignored when the distance between two discharge 210 points is greater than three times the discharge channel radius. Finally, the core wire 211 tends to equilibrium temperature. In motion mode 2, the discharge centers are in the 212 same position. During the increase of discharge times, the core wire's temperature 213 increases continuously due to the superposition of energy.

214 We take the final temperature at the discharge center as the dynamic equilibrium 215 temperature of the core wire. According to the ANSYS simulation results, the 216 relationship between the core wire equilibrium temperature and the pulse interval time 217 in movement model 2 has obtained, as shown in Fig.7. 


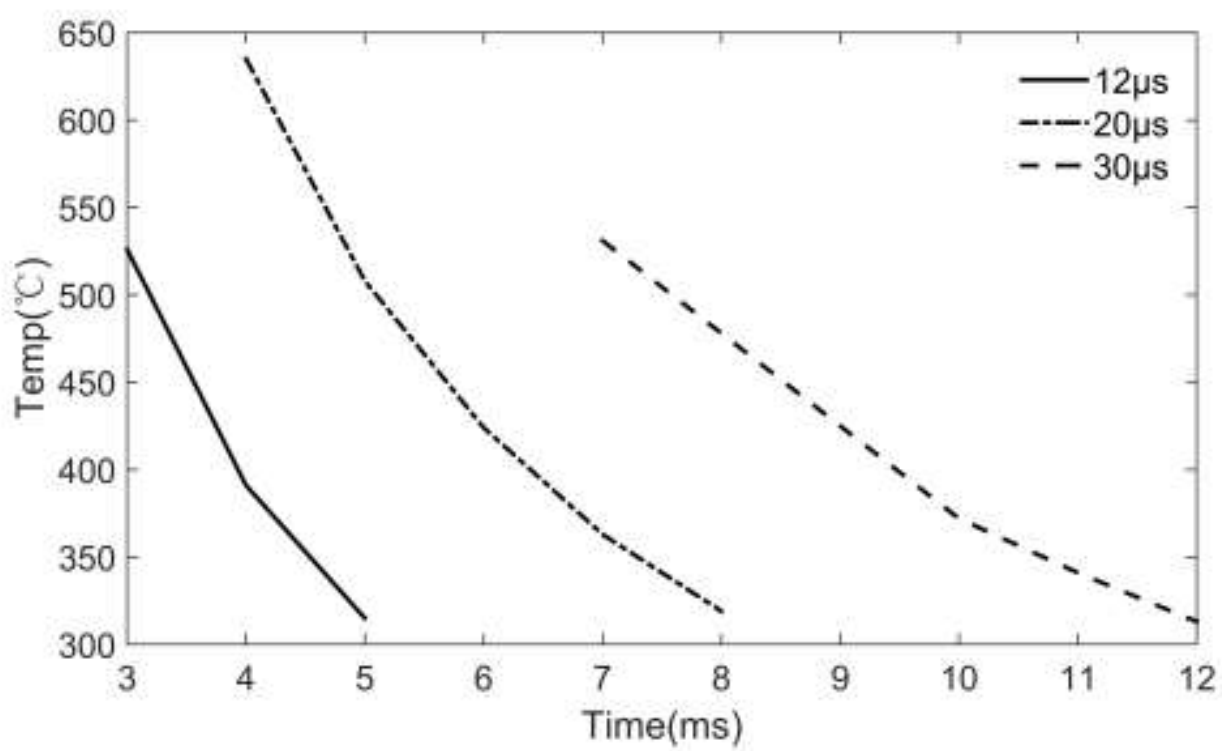

Fig.7 The relationship of balance temperature of wire and pulse interval duration

\section{Experiments}

222 The manufacturing experiment is carried out on a self-made ESD machine, and the 223 saw wire was deposited from one side. The experimental parameters are described in 224 Table 1.

Table. 1 Experiment parameter

\begin{tabular}{|c|c|c|c|c|c|c|c|c|c|c|}
\hline Parameter & \multicolumn{10}{|c|}{ Value } \\
\hline Workpiece (Cathode) & \multicolumn{10}{|c|}{$304-\mathrm{ss}(\phi 0.2 \mathrm{~mm})$} \\
\hline Electrode (Anode) & \multicolumn{10}{|c|}{$\mathrm{Cu}(10 \mu \mathrm{m}): \mathrm{Ni}(10 \mu \mathrm{m}):$ Diamond=12:12:1 } \\
\hline Coated diamond & \multicolumn{10}{|c|}{ W40 } \\
\hline Current(A) & \multicolumn{10}{|c|}{19} \\
\hline Pulse duration time $(\mu \mathrm{s})$ & \multicolumn{4}{|c|}{12} & \multicolumn{3}{|c|}{20} & \multicolumn{3}{|c|}{30} \\
\hline Pulse interval time(ms) & 1 & 3 & 4 & 5 & 4 & 6 & 8 & 6 & 8 & 10 \\
\hline Working medium & \multicolumn{10}{|c|}{ Air } \\
\hline Movement mode & \multicolumn{10}{|c|}{2} \\
\hline Discharge time(s) & \multicolumn{10}{|c|}{0.4} \\
\hline
\end{tabular}

The mechanical properties of the 304-ss wire changed because of the microstructure's

226 transformation. Because it is slender, the change of local structure will affect the 227 overall performance of the core wire. Researchers have reported that the martensitic 228 transformation of $304-s s$ begins at $300^{\circ} \mathrm{C}$ [26]. Therefore, the local equilibrium 229 temperature of the saw wire should maintain at about $300^{\circ} \mathrm{C}$ during the ESDDSW 230 process. Therefore, select the pulse interval time should base on the discharge 
231 parameters. In the experiment, when the pulse duration time is $12 \mu \mathrm{s}$, the pulse interval 232 time is set to $1 \mathrm{~ms}, 3 \mathrm{~ms}, 4 \mathrm{~ms}$, and $5 \mathrm{~ms}$. When the pulse duration time is $20 \mu \mathrm{s}$, the 233 pulse interval time is set to $4 \mathrm{~ms}, 6 \mathrm{~ms}$, and $8 \mathrm{~ms}$. When the pulse duration time is $30 \mu \mathrm{s}$, 234 the pulse interval time is set to $6 \mathrm{~ms}, 8 \mathrm{~ms}$, and $10 \mathrm{~ms}$. During the experiment, when the 235 pulse duration time is $12 \mu \mathrm{s}$ and the pulse interval time is $1 \mathrm{~ms}$, the saw wire is broke 236 frequently. And the saw wire deforms obviously after deposition. Under other 237 parameters, the saw wire does not break, and the saw wire keeps its original shape.

238 Tensile tests have been carried out on the deposited wire saw, and the 239 load-displacement curve is shown in Fig.8. It can be seen that: when the pulse 240 duration time is $12 \mu \mathrm{s}$ and the pulse interval time is $1 \mathrm{~ms}$, the wire breaking force is $24110 \mathrm{~N}$ lower than that of the raw wire. And its ductility is also greatly reduced. Under 242 other parameters, with the decrease of pulse interval time, the broken force of the saw 243 wire does not decrease obviously, but its ductility also decreases gradually. It 244 indicated that the pulse interval would first affect the plasticity of the wire saw. And 245 when it exceeds a certain range, it would affect the tensile strength of the wire saw. 246 Therefore, in order to maintain its mechanical performance, the balance temperature 247 of the wire saw should be around $300^{\circ} \mathrm{C}$ during the ESDDWS process.

(a)

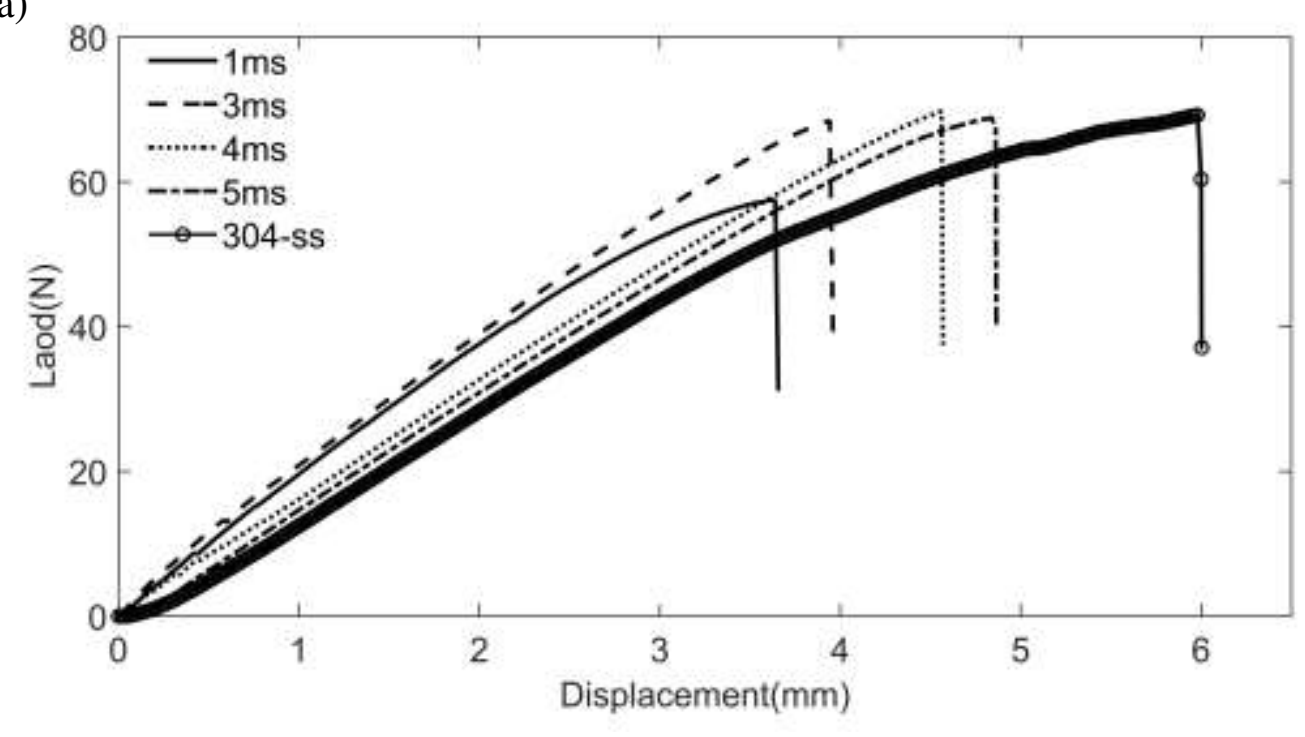


(b)

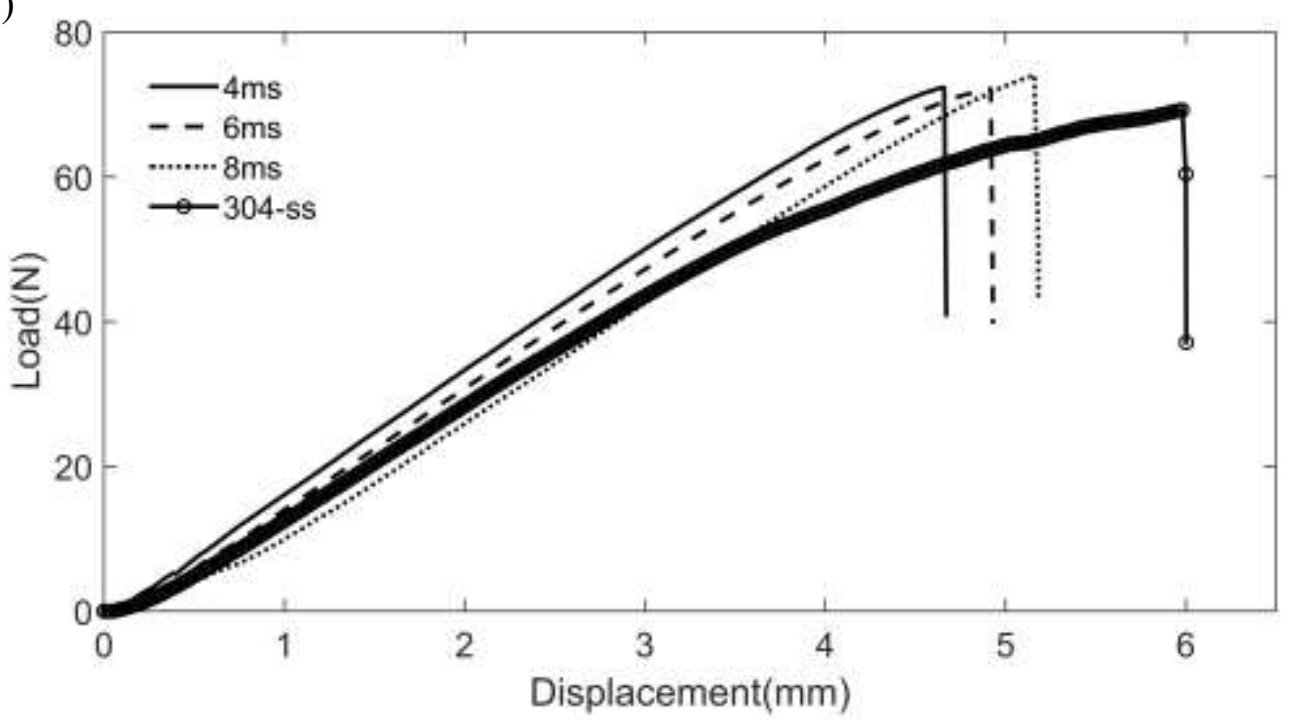

(c)

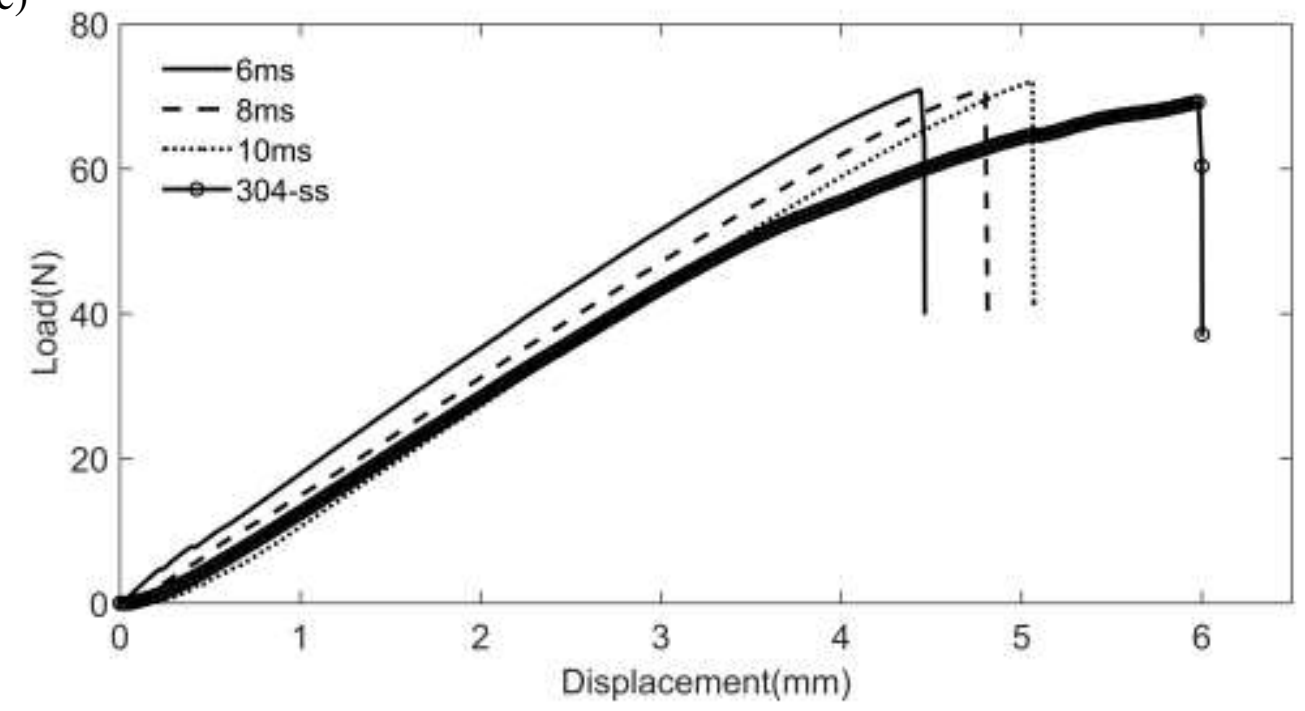

Fig.8 Load and displacement curve of tensile test:(a) $12 \mu \mathrm{s}$; (b) $20 \mu \mathrm{s}$; (c) $30 \mu \mathrm{s}$

\section{Conclusion}

253 (1) According to the process characteristics of ESDDWS, two kinds of motion modes 254 of manufacturing are put forward.

255 (2) According to the characteristics of the saw wire, a simulation model of continuous 256 pulse discharge deposition is established.

257 (3) According to the two different motion modes of electrode and core wire, the 258 thermal simulations of continuous pulse discharge of ESDDWS were analyzed.

259 (4) The simulation results show that: in movement mode 1 , the temperature of 260 adjacent discharge points has the superposition effect. The effect of temperature 261 superposition can be ignored when the distance between two discharge points is 
262 greater than three times the discharge channel radius. The wire saw's temperature 263 tends to balance finally. In motion mode 2, the discharge centers are in the same 264 position. During the increase of discharge times, the core wire's temperature increases 265 continuously due to the superposition of energy.

266 (5) The pulse interval would first affect the plasticity of the wire saw. And when it 267 exceeds a certain range, it would affect the tensile strength of the wire saw. In order to 268 maintain its mechanical performance, the balance temperature of the wire saw should 269 be around $300^{\circ} \mathrm{C}$ during the ESDDWS process.

271 Acknowledgment

272 This work is financially supported by the National Natural Science Foundation of 273 China (No.51775317); the Key Research and Development Program of Shandong 274 Province, China (No.2019JZZY020209)

\section{Declarations}

277 Ethical approval

278 Not applicable

280 Consent to participate

281 Not applicable

\section{Consent to publish}

284 The authors declare that this work has not been submitted elsewhere for publication, 285 in whole or in part.

\section{Authors contributions}

288 Chengyun $\mathrm{Li}$ is the executor of article writing and experiment operation.

289 Peiqi Ge contributed to the conception of the work.

290 Wenbo Bi contributed to the experiment preparation.

\section{Funding}

293 This work is financially supported by the National Natural Science Foundation of

294 China (No.51775317); the Key Research and Development Program of Shandong

295 Province, China (No.2019JZZY020209)

\section{Competing interests}


298 We declare that we have no financial and personal relationships with other people or 299 organizations that can inappropriately influence our work. We have no competing 300 financial interests.

301

302 Code availability

303 Not applicable.

304

305 Data availability

306 The data and materials supporting the results of this article are included within the 307 article.

308 


\section{References}

310 [1] Yadlapalli R, Kotapati A, Kandipati R, Balusu S, Koritala C. (2021) Advancements 311 in energy efficient GaN power devices and power modules for electric vehicle 312 applications: a review. Int J Energ Res.

313 [2] Wellmann P. (2017) Power electronic semiconductor materials for automotive and 314 energy saving applications - SiC, GaN, Ga2O3, and Diamond. Z Anorg Allg Chem. $315 \quad$ 643(21), 1312-1322.

316 [3] Gao Y, Chen Y. (2019) Sawing stress of SiC single crystal with void defect in 317 diamond wire saw slicing. Int J Adv Manuf Tech. 103(1-4), 1019-1031.

318 [4] Garrido D, Baraia I.(2017) Review of wide bandgap materials and their impact in 319 new power devices. IEEE (ECMSM). Donostia-San Sebastian, Spain.

320 [5] Gao Y, Chen Y, Ge P, Zhang L, Bi W. (2018) Study on the subsurface microcrack 321 damage depth in electroplated diamond wire saw slicing SiC crystal. Ceram Int. 44(18), 22927-22934.

[6] Chung C, Tsay G, Tsai M. (2014) Distribution of diamond grains in fixed abrasive wire sawing process. Int J Adv Manuf Tech. 73(9-12), 1485-1494.

[7] Huang H, Zhang Y, Xu X. (2015) Experimental investigation on the machining characteristics of single-crystal SiC sawing with the fixed diamond wire. Int J Adv Manuf Tech. 81(5-8), 955-965.

[8] Kim D, Kim H, Lee S, Jeong H. (2015) Effect of initial deflection of diamond wire on thickness variation of sapphire wafer in multi-wire saw. Int J Pr Eng Man-Gt. 2(2), 117-121.

[9] Huang H, Li X, Xu X. (2017) An experimental research on the force and energy

334 [10]Tsai P, Chou Y, Yang S, Chen Y, Wu C.(2013) A comparison of wafers sawn by resin bonded and electroplated diamond wire - from wafer to cell. IEEE (PVSC).Tampa, FL. 523-525.

[11] Liu T, Ge P, Gao Y, Bi W. (2017) Depth of cut for single abrasive and cutting force in resin bonded diamond wire sawing. Int J Adv Manuf Tech. 88(5-8), 1763-1773. 
[12]Kim H, Kim D, Kim C, Jeong H. (2013) Multi-wire sawing of sapphire crystals with reciprocating motion of electroplated diamond wires. CIRP Annals. 62(1), $335-338$.

[13] Sheldon G, Johnson R. (1985) Electro-spark deposition: A technique for producing wear resistant coatings. Wear Mater: Int. Conf. Wear Mater. 388-396.

[14]Wang P, Pan G, Zhou Y, Qu J, Shao H. (1997) Accelerated electrospark deposition and the wear behavior of coatings. J Mater Eng Perform. 6(6), 780-784.

[15]Chakraborty S, Kar S, Dey V, Ghosh S. (2018) The phenomenon of surface modification by electro-discharge coating process: A review. Surf Rev Lett. 25(01), 1830001-1830003.

[16] Adam B, Wood W, Kadali J, Talla R, Langston T. (2017) Heat affected zone formation in electrospark deposition additive manufacturing on ultrahigh strength steel. Mater Perform Charact. 6, 375-393.

[17]Peng Z, Li Y. (2012) The deposition and removal process for micro machining based on electrical discharge. Adv Mater Res. 472-475, 2448-2451.

[18]Jain V, Seshank S, Sidpara A, Jain H.(2013) Some aspects of micro-fabrication using electro-discharge deposition process. ASME/ISCIE (ISFA2012),St Louis, MO. 419-424.

[19]Mohri N, Saito N, Tsunekawa Y, Kinoshita N. (1993) Metal surface modification by electrical discharge machining with composite electrode. CIRP Annals - Manuf Techno. 42(1), 219-222.

[20]Furutani K, Suzuki K. (2015) Experimental investigations of deposition conditions for saw wire fabrication by electrical discharge machining. Int J Adv Manuf Tech. 76(9-12), 1643-1651.

[21]Furutani K, Kanai M, Mieda Y, Suzuki M. (2010) Proposal of abrasive layer fabrication on thin wire by electric discharge machining. Int J Automation Technol. 4(4), 394-398.

[22]Furutani K, Suzuki K. (2009) A desktop saw wire coating machine by using electrical discharge machining. IEEE Int Conf Cont Autom. Christchurch, New Zealand. 2165-2170. 
369 [23]Li C, Ge P, Bi W. (2021) Thermal simulation of the single discharge for 370 electro-spark deposition diamond wire saw. Int J Adv Manuf Tech.

371 [24]Wang Y, Xie B, Wang Z, Peng Z. (2011) Micro EDM deposition in air by single 372 discharge thermo simulation. T Nonferr Metal Soc. 21(s2), 450-455.

373 [25] Shahri H, Mahdavinejad R, Ashjaee M, Abdullah A. (2017) A comparative 374 investigation on temperature distribution in electric discharge machining process 375 through analytical, numerical and experimental methods. Int J Mach Tools Manuf.

377 [26] Alinia S, Khamedi R, Ahmadi I. (2018) An investigation into deep drawing 378 parameters on deformation induced martensitic microstructure transformation of 379 an austenitic stainless steel. Metallogr, Microstruct, Anal. 7(6), 724-734. 


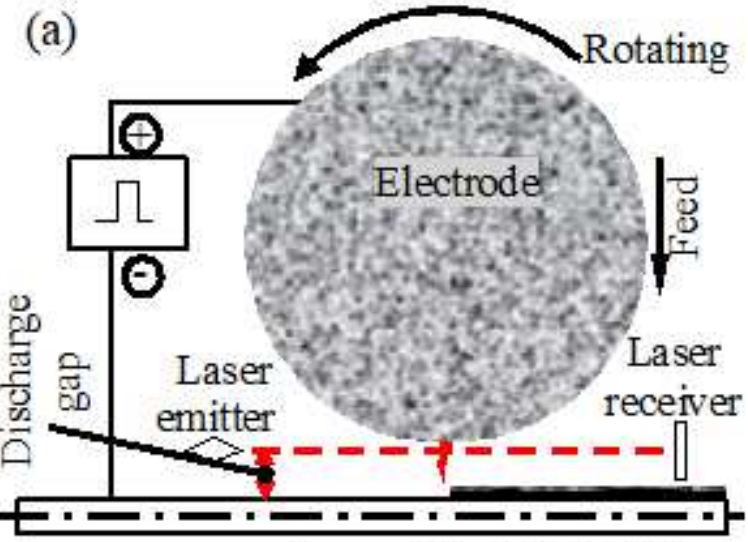

$\longrightarrow$ Wire feed

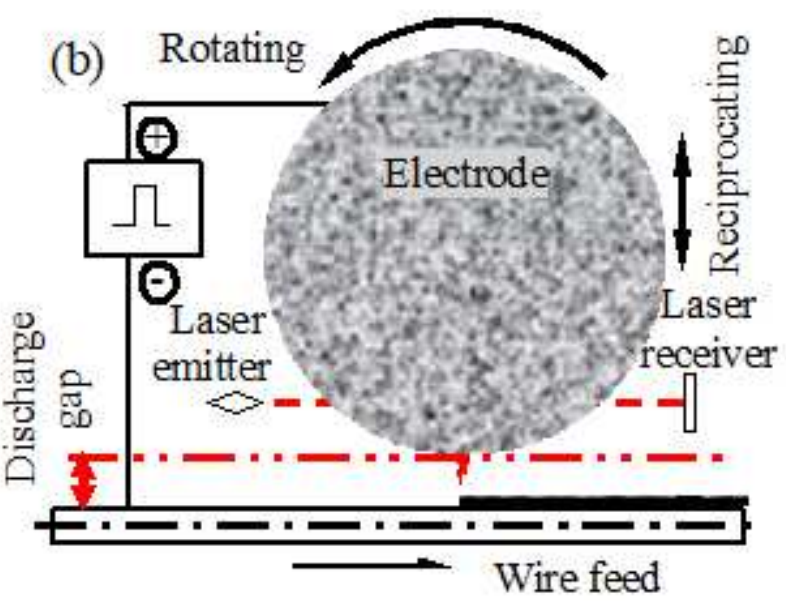

Figure 1

Move model of electrode and wire
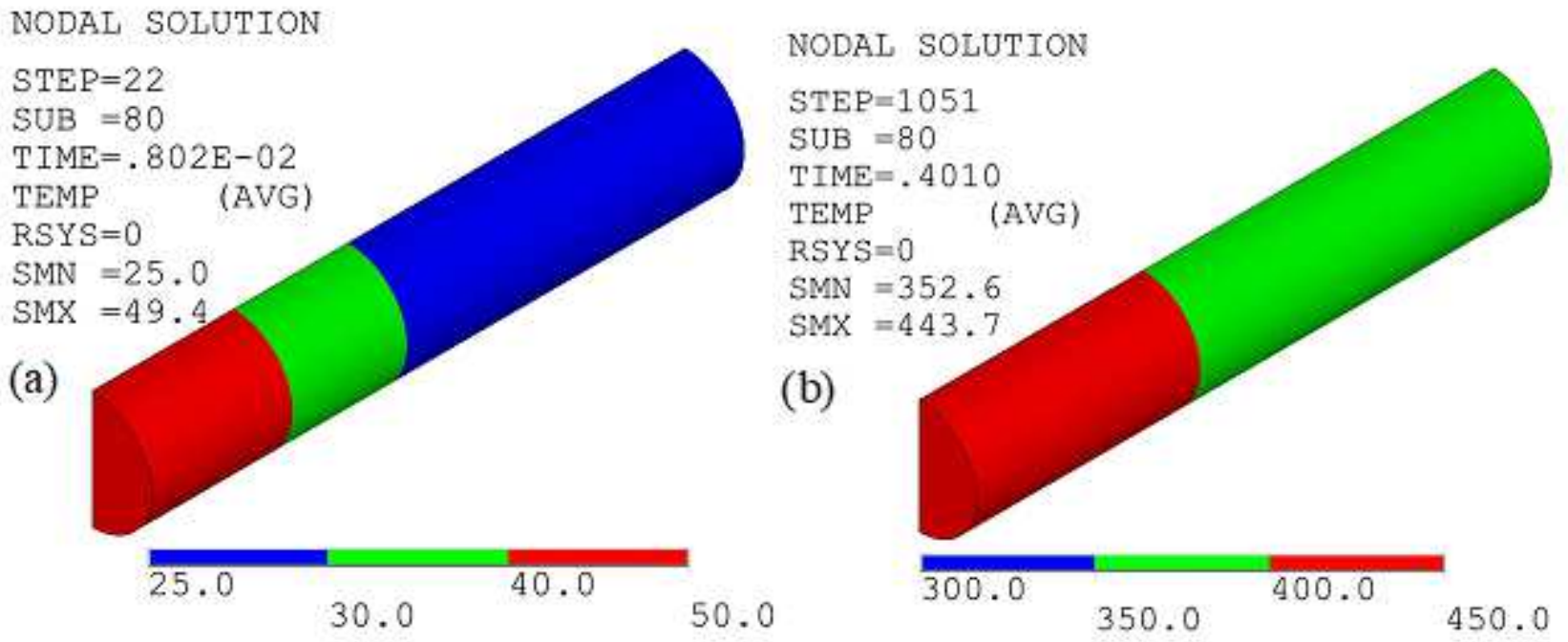

Figure 2

Temperature field of ESDDWS: (a) Single period temperature field; (b) Continuous pulse discharge temperature field without infinite element 
(a)

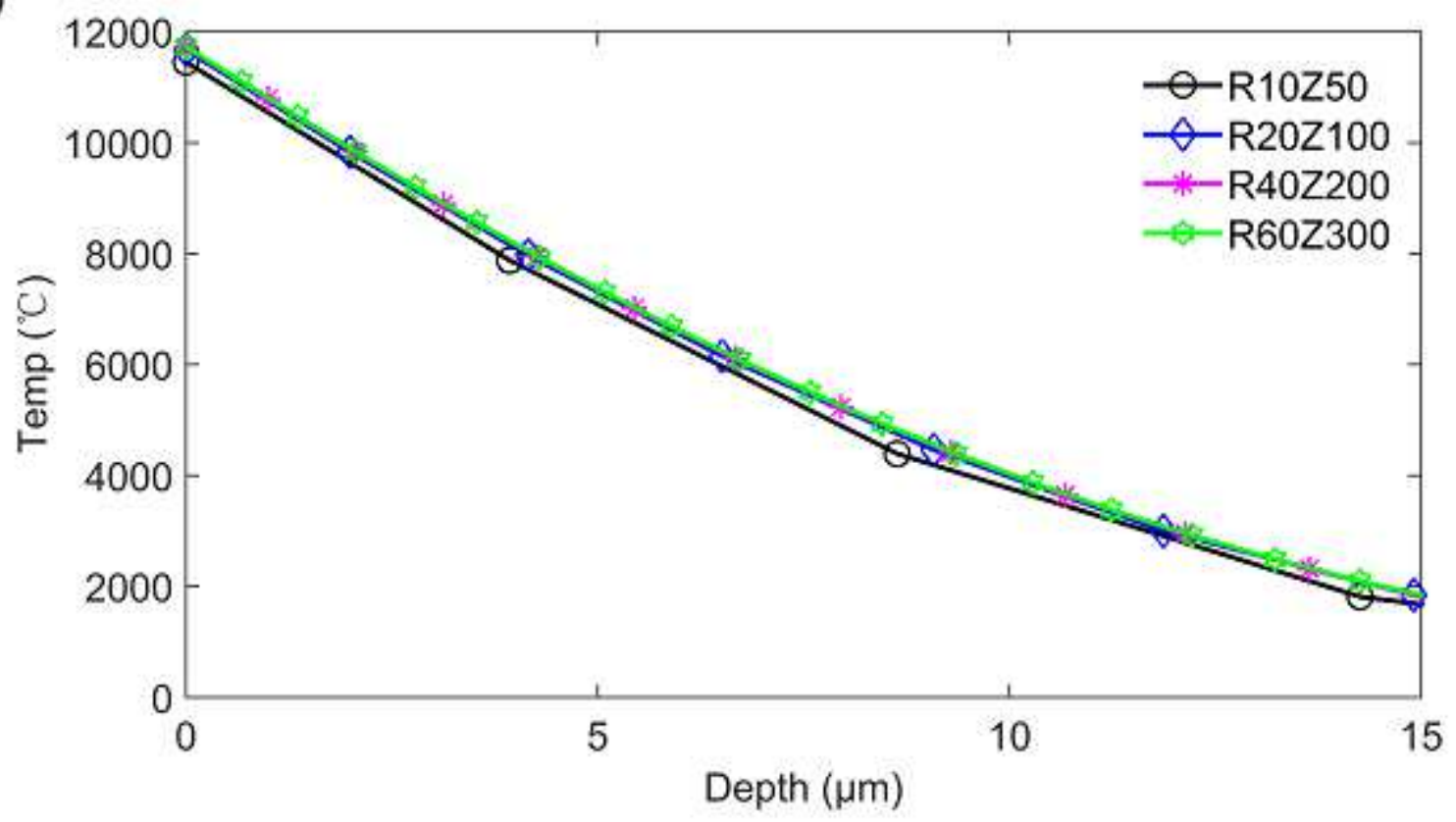

(b)

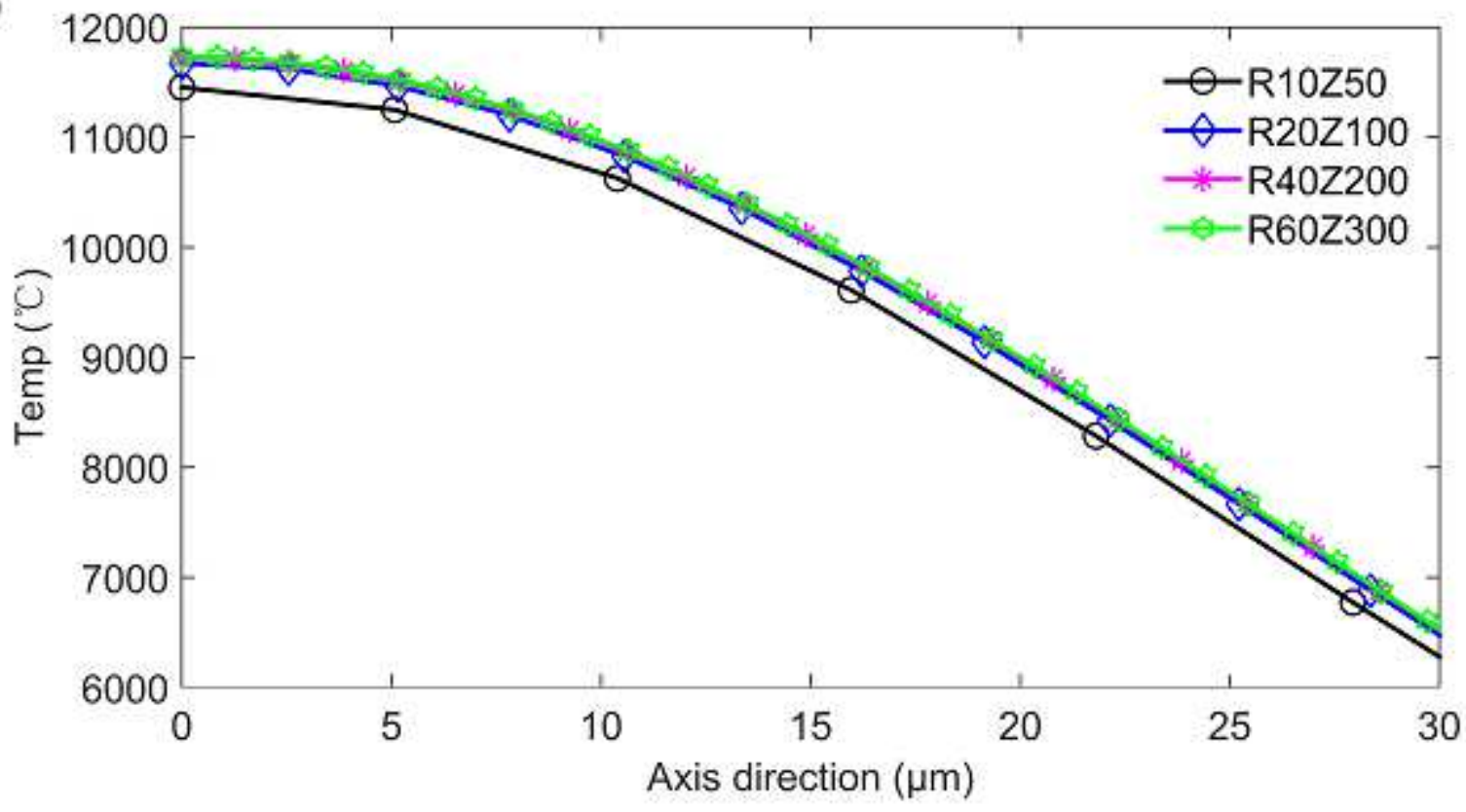

Figure 3

The element independence analysis: (a) depth direction; (b) axis direction 


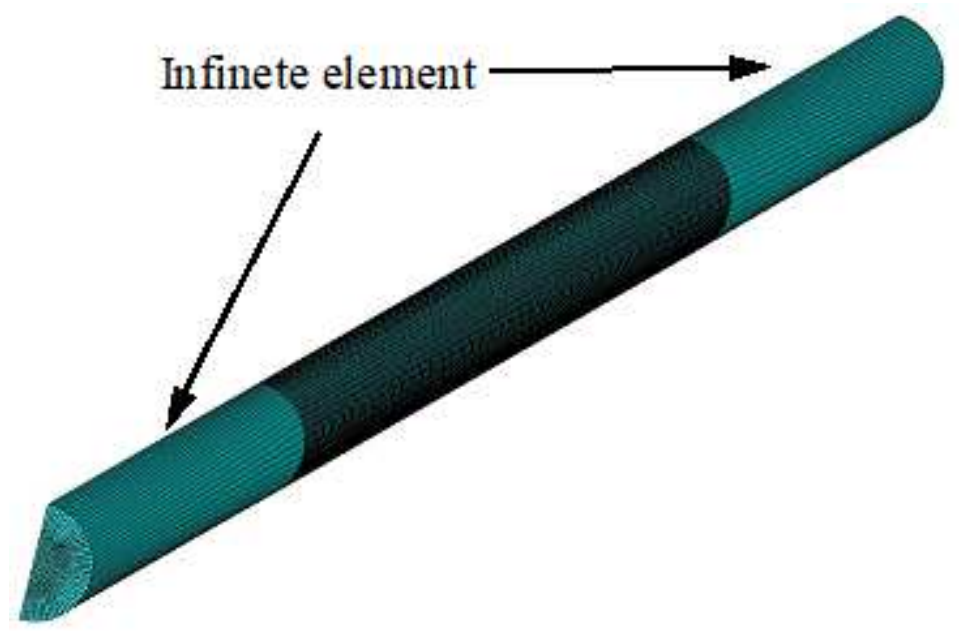

\section{Figure 4}

Meshing model of saw wire

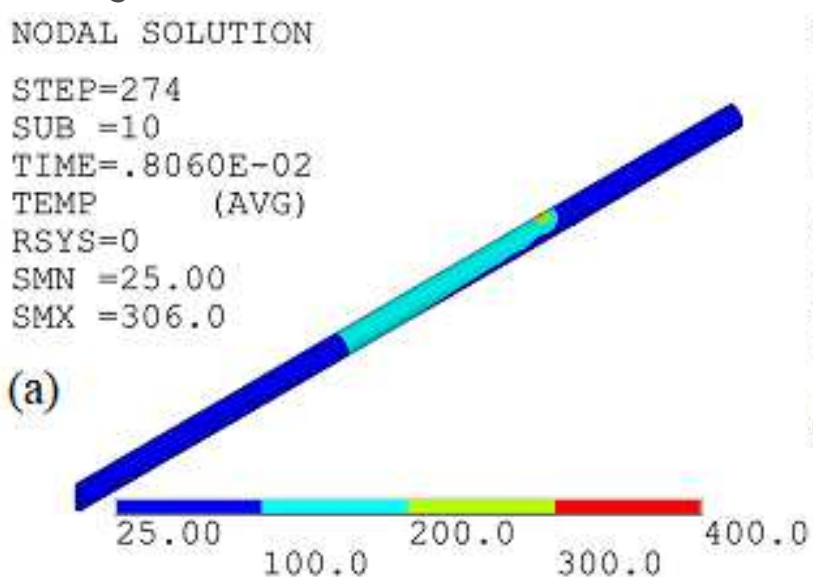

NODAL SOLUTION

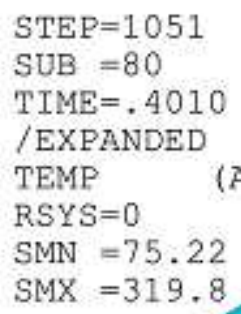

(b)

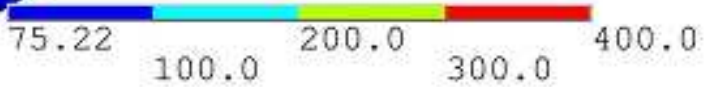

Figure 5

Temperature field of continuous pulse discharge deposition: (a) move motion 1; (b) move motion 2 
(a)

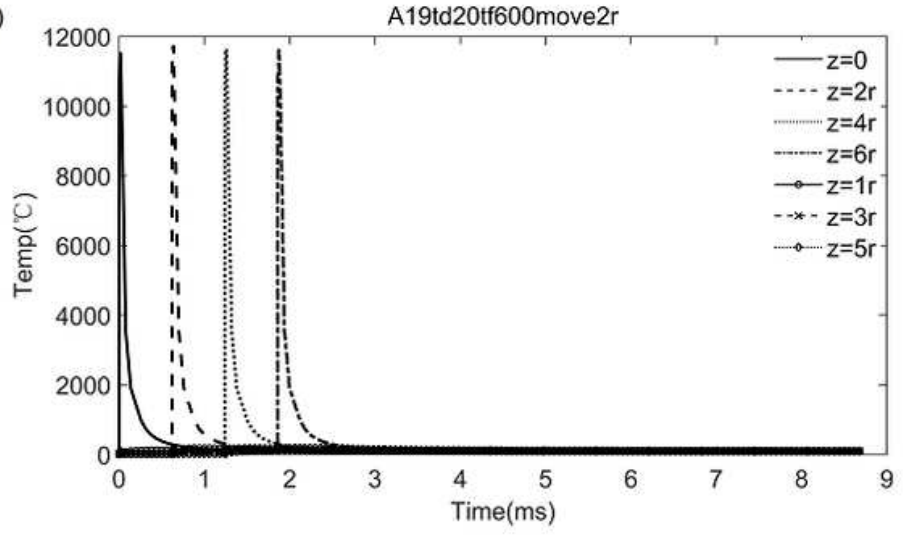

(b)

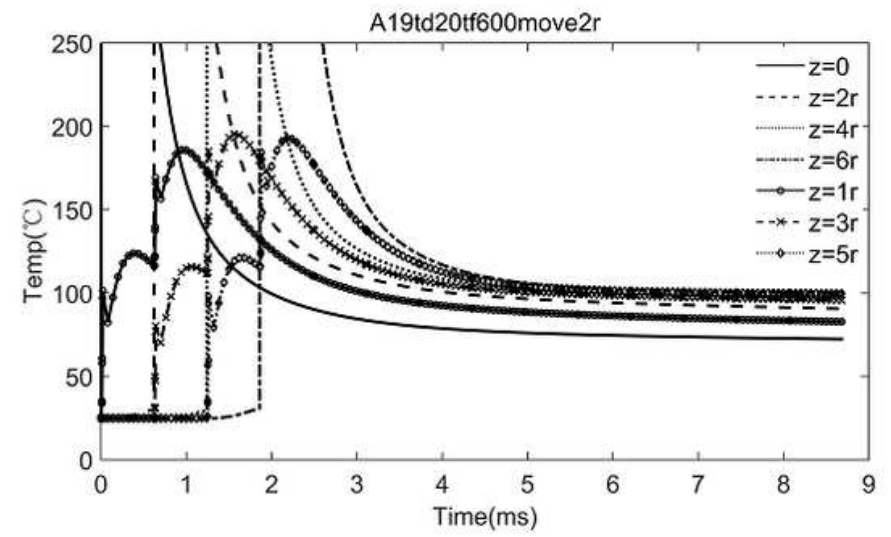

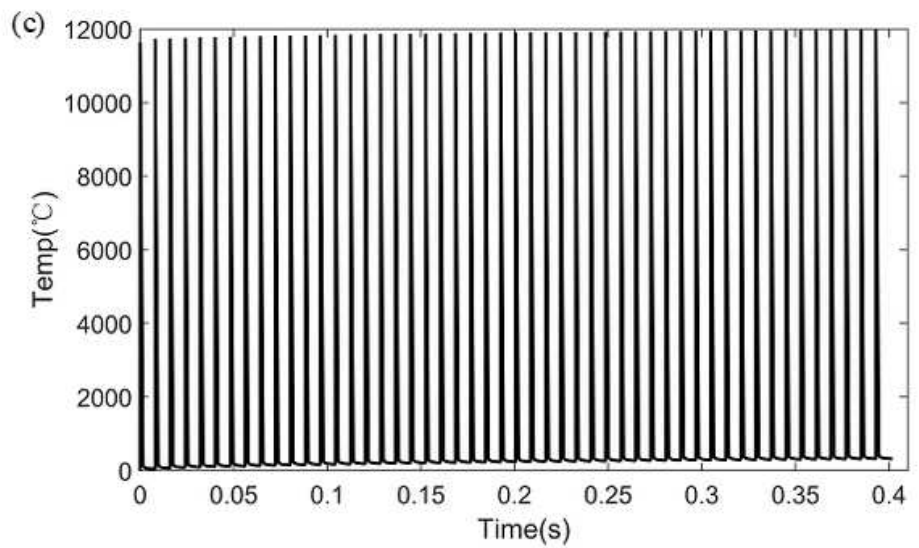

(d)

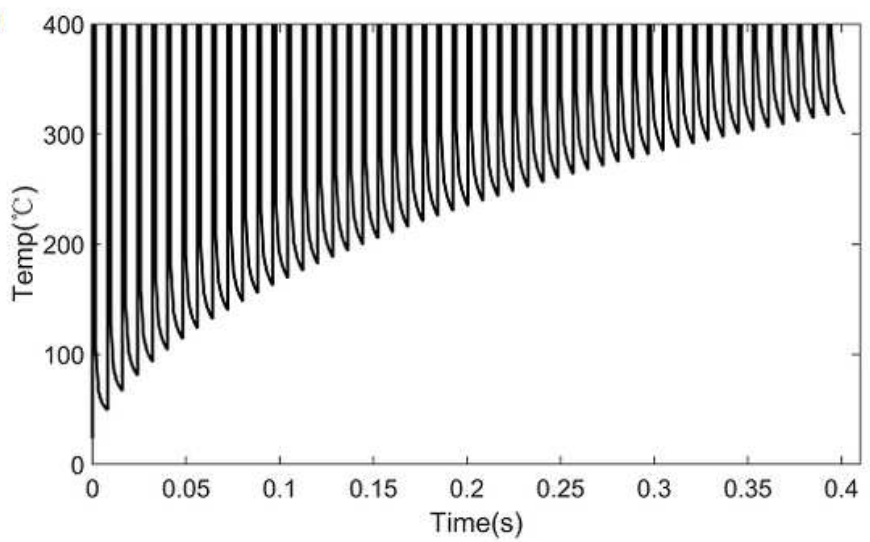

Figure 6

Temperature curve of the discharge center; (a) move model 1; (b) low-temperature stages of move model 1 ; (c) move model 2;(d) low-temperature stages of move model 2

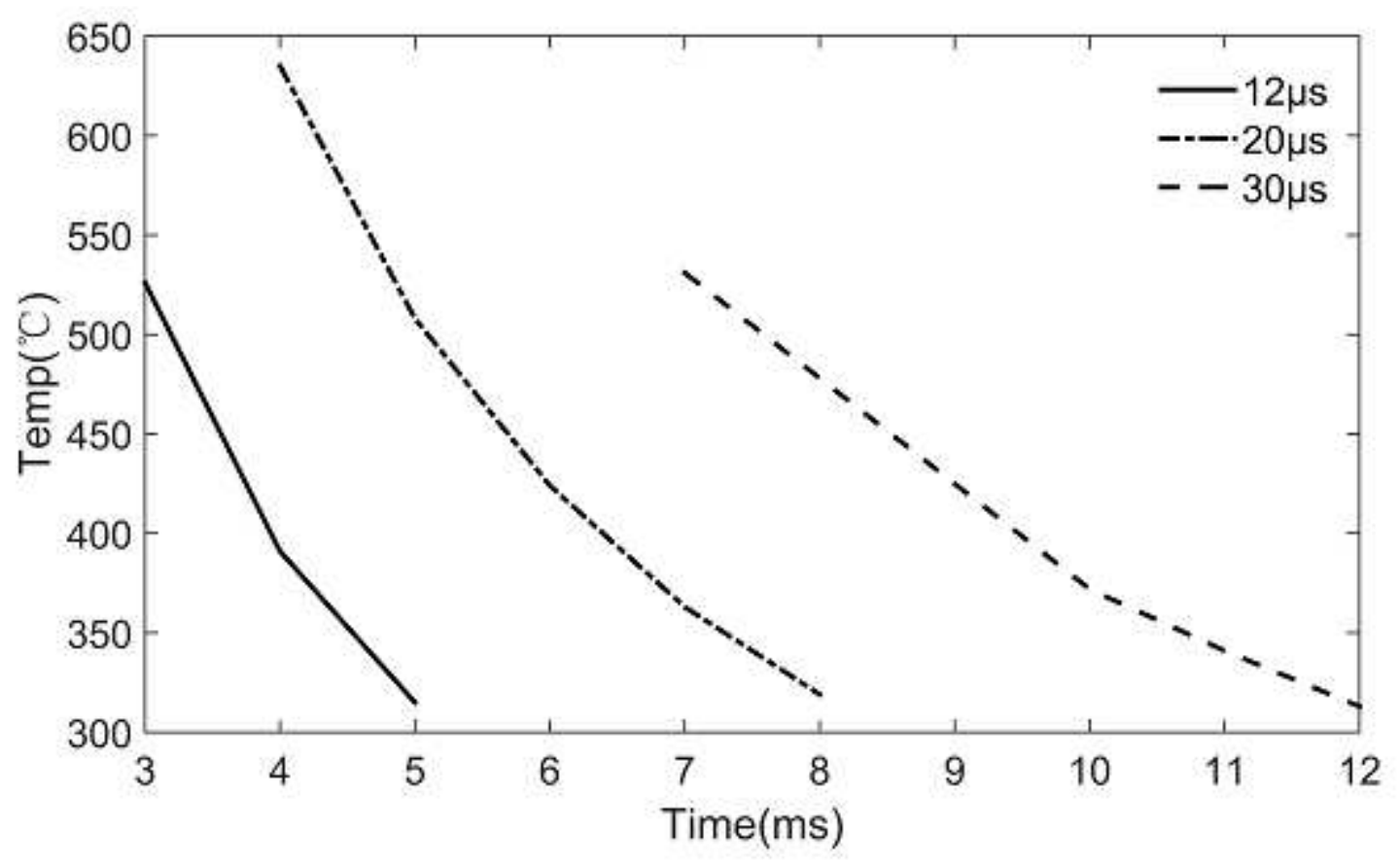


Figure 7

The relationship of balance temperature of wire and pulse interval duration time(move model 2)

(a)

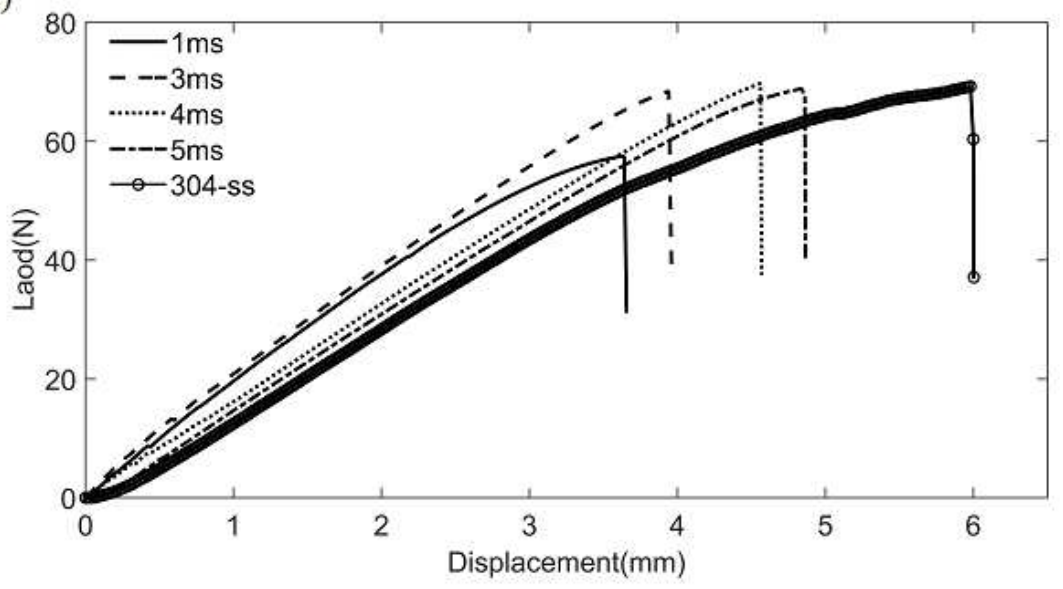

(b)

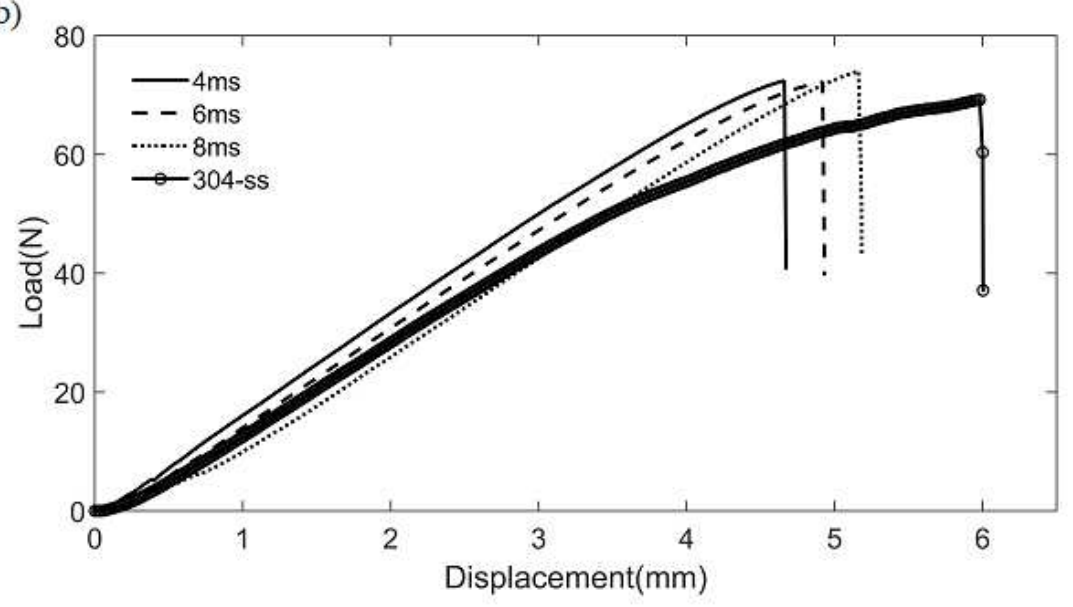

(c)

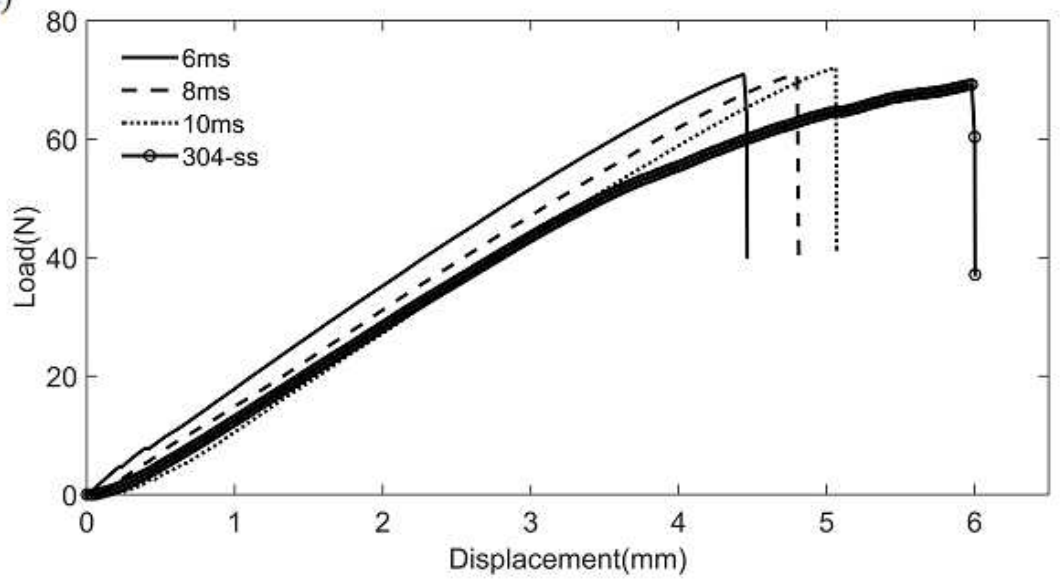

Figure 8

Load and displacement curve of tensile test:(a) $12 \mu \mathrm{s}$; (b) $20 \mu \mathrm{s}$; (c) $30 \mu \mathrm{s}$ 